\title{
A New Minimum Delay Model for Multi-Lane Traffic Circles
}

\author{
Serhan TANYEL ${ }^{1}$ \\ Süheyla Pelin ÇALIŞKANELLI' ${ }^{2}$ \\ Mustafa ÖZUYSAL ${ }^{3}$
}

\begin{abstract}
Minimum delay (or service delay) is one of the most important performance measures for intersection analysis. It can be described as the delay to a vehicle, which is waiting at the stop (or yield) line of an unsignalized intersection. In this study, an appropriate minimum delay equation is derived for multi-lane traffic circles in İzmir, Turkey. For this purpose, observations are made at six approaches of five multi-lane traffic circles. Simple and multiple regression analysis, in which circulating flow and geometric parameters are chosen as independent variables, are used to model minimum delay. Results have shown that geometry of a traffic circle has an important effect on minimum delay and should be considered in analysis but the model may fail to define minimum delay values greater than 22 seconds. Analyses have shown that models which depend on entry capacity are more effective in estimation of minimum delay at multi-lane traffic circles.
\end{abstract}

Keywords: Minimum delay, traffic circles, unsignalized intersections.

\section{INTRODUCTION}

Traffic circle is one of the most preferred intersection types in Turkey. However, because of poor design implementations and lack of appropriate capacity and performance analysis procedures, traffic signals are frequently deployed at traffic circles especially in urban areas. Therefore, research on capacity and performance of traffic circles has great importance. Several studies have been presented on capacity of traffic circles like Tanyel et al. [1], Özuysal et al. [2], Çalışkanelli et al. [3], Tanyel and Yayla [4, 5] and Ersoy and

\footnotetext{
Note:

- This paper was received on April 25, 2019 and accepted for publication by the Editorial Board on August 14, 2020.

- Discussions on this paper will be accepted by March 31, 2022.

- https://doi.org/10.18400/tekderg.557823

1 Dokuz Eylül University, Department of Civil Engineering, İzmir, Turkey - serhan.tanyel@deu.edu.tr https://orcid.org/0000-0001-8549-9442

2 Dokuz Eylül University, Department of Civil Engineering, İzmir, Turkey - pelin.caliskanelli@deu.edu.tr https://orcid.org/0000-0002-0530-3276

3 Dokuz Eylül University, Department of Civil Engineering, İzmir, Turkey - mustafa.ozuysal@deu.edu.tr https://orcid.org/0000-0002-3276-3075
} 
Çelikoğlu [6]. However only a limited number of studies like Tanyel et al. [7] have been conducted on performance of traffic circles.

Delay can be used in designing, operating and comparing the performance of intersections under different control and flow conditions, as it directly reflects side effects of traffic flow like fuel consumption increase, driver dissatisfaction and increased travel time [8]. Akçelik [9] has defined delay as "the difference between interrupted and uninterrupted travel times through the intersection". A general form of the equation for average delay per vehicle $\left(D_{a v}\right)$ can be expressed as [10]:

$$
D_{a v}=D_{\min } \cdot\left(1+\frac{\gamma+\varepsilon \cdot \rho}{1-\rho}\right)
$$

where $\gamma$ and $\varepsilon$ are constants, $\rho$ is the degree of saturation and $D_{\min }$ is minimum delay (seconds). Troutbeck [11, 12] has defined $\gamma$ and $\varepsilon$ constants according to Cowan's [13] studies. The value of $\gamma$ depends on the arrival characteristics of minor stream flow: if minor stream vehicles arrive at random, then $\gamma$ is set to " 0 "; if the minor stream vehicles arrive in platoons, then $\gamma$ should be greater than " 0 ". For random stream arrivals, $\varepsilon$ can also be calculated by using the following equation:

$$
\varepsilon=\frac{e^{q_{c} T_{0}}-q_{c} T_{o}-1+q_{c}\left(e^{q_{c} T_{0}}-1\right) D_{\min }}{q_{c}\left(e^{q_{c} T_{0}}-1\right) D_{\min }}
$$

where $q_{c}$ is the major stream flow (veh/sec), $T_{o}$ is the follow-up time (seconds) and $\varepsilon$ is approximately equal to " 1.0 " $[10,12]$.

Minimum delay (or service delay) is an important component of average delay. It is the delay a driver will experience while waiting at the entry of minor approach of an unsignalized intersection or roundabout. Minimum delay can also be described as the delay a driver in the minor stream will experience when minor stream demand is nearly zero. Minimum delay starts when a minor stream vehicle reaches to the stop or yield line of an approach, includes the waiting time of the driver for an acceptable headway or gap in the major stream (critical gap) and ends when the vehicle enters and joins the major flow. In other words, minimum delay is the sum of waiting time of a vehicle at the entry of the intersection and follow-up time between entering vehicles in the minor approach [14]. The term minimum delay was first introduced by Adams in 1936 for pedestrians and since then minimum delay is named as Adams delay [15].

In the literature, like capacity of unsignalized intersections and traffic circles, two different methods (or approaches) are widely used for modeling minimum delay [14, 16, 17, 18, 19].

1. theoretical (or behavioural) models which mainly depend on critical gap acceptance method,

2. empirical models which mostly depend on field data and regression analysis. 
The first example of theoretical models is Adams' delay function [20]. He stated that traffic flow can be defined statistically as a Poisson process. According to this assumption, if the flow rate is $q_{c}(\mathrm{veh} / \mathrm{sec})$, then headways between vehicles are exponentially distributed with mean $1 / q_{c}$. By using these assumptions, Adams [20] suggested the following equation for average delay for pedestrians:

$$
E(D)=\frac{e^{-q_{c} T}-1}{q_{c}}-T
$$

where $T$ is the accepted gap in seconds between vehicles by a pedestrian waiting on the sidewalk or at the roadside (if the minimum acceptable major-stream headway " $T$ " is assumed to be equal for all pedestrians or vehicles waiting at the entry of a minor approach, then it is called as critical gap). However, previous studies have shown that, while the upper tail of observed headways can be defined by a negative exponential distribution, the lower tail of the headways are influenced by a safety headway (or following distance), which can be defined as the minimum headway between vehicles in the major flow $(\Delta)[21,22,23$, 24]. Thus in another early study on traffic engineering, Tanner [21] assumed that the vehicles in the major stream follow each other with headways, which can be modeled with shifted negative exponential distribution and suggested the following equation for estimating minimum delay at unsignalized intersections:

$$
D_{\min }=\frac{e^{q_{c}(T-\Delta)}}{q_{c} \cdot\left(1-\Delta \cdot q_{c}\right)}-T-\frac{1-\Delta \cdot q_{c}+\Delta^{2} \cdot q_{c}^{2}}{q_{c} \cdot\left(1-\Delta \cdot q_{c}\right)}+\frac{1 / 2 \cdot \Delta^{2} \cdot q_{c}}{\left(1-\Delta \cdot q_{c}\right)^{2}}
$$

where $\Delta$ is the minimum headway between major-stream vehicles (seconds) and $T$ is the critical gap (seconds). Tanner [21] derived Equation 4 for the condition that there is only one lane in the major road. For two-lane major stream, he stated that minimum headway between vehicles can be assumed as zero and headways between vehicles can be modeled by using negative exponential distribution.

Drew [25] used Erlang distribution for modeling headways in major flow and he developed an equation for modeling service delay of entering vehicles from minor approach:

$$
D_{\min }=\frac{e^{k \cdot q_{c} \cdot T}-\sum_{i=0}^{k} \frac{\left(k \cdot q_{c} \cdot T\right)^{i}}{i !}}{q_{c} \cdot \sum_{i=0}^{k} \frac{\left(k \cdot q_{c} \cdot T\right)^{i}}{i !}}
$$

Here " $k$ " is the Erlang number. If " $k=1$ " then the equation transforms into the following form, which was suggested by Ashworth [26]: 
$D_{\min }=\frac{\left(e^{q_{c} \cdot T}-1-q_{c} \cdot T\right)}{q_{c}}$

Studies have shown that minimum delay $\left(D_{\min }\right)$ highly depends on the platooning characteristics of major flow [10]. For this reason, mixed distributions like Hyperexpoential, Hyperlang, Cowan M3 (or M/D/1 model) or Cowan M4 (or M/G/1 model) are started to be used in modeling headways in the major flow, and thus delay models started to be developed by using these distributions. One of the most known model is suggested by Troutbeck $[11,27]$. He used Cowan M3 distribution instead of shifted negative exponential distribution and suggested the following function which is also used for estimating the performance of roundabouts in Sweden [28]:

$D_{\min }=\frac{e^{\lambda \cdot(T-\Delta)}}{\alpha \cdot q_{c}}-T-\frac{1}{\lambda}+\frac{\lambda \cdot \Delta^{2}-2 \cdot \Delta+2 \cdot \Delta \cdot \alpha}{2 \cdot(\lambda \cdot \Delta+\alpha)}$

where $\alpha$ is the proportion of free vehicles and $\lambda$ is a decay constant which can be found by using the following formula:

$\lambda=\frac{\alpha q_{c}}{1-\Delta q_{c}}$

For two major streams, Equation 5 is rewritten as:

$\mathrm{D}_{\min }=\frac{e^{-\Lambda(T-\Delta)}}{\left(q_{1}+q_{2}\right) A}-T-\frac{1}{\Lambda}+\frac{\Lambda \Delta^{2}+2 \Lambda \Delta+2 \beta \Delta^{2}-4 / 3 \Lambda \Delta^{3} \beta}{2 \Lambda \Delta+2 A-2 \Lambda \beta \Delta^{2}}$

where

$\beta=\frac{q_{1} q_{2}}{q_{1}+q_{2}}$

$A=\frac{\alpha_{1} q_{1}\left(1-\Delta q_{2}\right)+\alpha_{2} q_{2}\left(1-\Delta q_{1}\right)}{q_{1}+q_{2}}$

$\Lambda=\lambda_{1}+\lambda_{2}$

In the equations, $q_{1}$ and $q_{2}$ are the traffic flows on lanes 1 and $2, \alpha_{1}$ and $\alpha_{2}$ are the proportion of free vehicles on major streams 1 and 2 , and $\lambda_{1}$ and $\lambda_{2}$ are the decay constants.

Flannery et al. [29] have developed a general formula for expected value of minimum delay: 


$$
E\left(D_{\min }\right)=\frac{1}{\bar{t}}\left(\frac{1}{2} T^{2}-\int_{0}^{T} t F(t) d t+(1-F(T))^{-1}\left(T-\int_{0}^{T} F(t) d t \int_{0}^{T} t d F(t)\right)\right)
$$

In Equation 13, $F(T)$ is the probability distribution of accepted gaps, $t$ is headway between vehicles in the major stream (seconds), $\bar{t}$ is the mean headway (seconds) and $F(t)$ is the probability distribution of a general distribution used for modeling headways. If the general distribution is assumed as negative exponential distribution then Equation 13 may reduce to Adams' delay model given in Equation 3.

Besides the models presented above, some empirical minimum delay models have been developed especially for stop controlled intersections. One of the first empirical models is suggested by Kyte et al. [18]:

$$
D_{\min }=17.28 Q_{c}
$$

where $Q_{c}$ is the conflicting flow in front of the minor stream flow (veh/h). This function is valid for conflicting traffic volumes that range between $0.051 \sim 0.31 \mathrm{veh} / \mathrm{sec}$.

Al-Omari and Benekhoal [19] suggested different equations of minimum delay calculation for different maneuver types from a minor approach as follows:

$$
\begin{aligned}
& D_{\min R}=3.28+0.00886 Q_{R} \\
& D_{\min T H}=3.59+0.00730 Q_{T H} \\
& D_{\min L}=3.25+0.01070 Q_{L}
\end{aligned}
$$

where $D_{\text {mini }}$ is the delay for the $i$ th maneuver (seconds); $\mathrm{Q}_{\mathrm{i}}$ is the conflicting flow in front of the minor stream approach $i$ th maneuver $(\mathrm{veh} / \mathrm{hr})$ and $\mathrm{R}, \mathrm{L}$ and $\mathrm{TH}$ indices denote right turning, left turning and through passing maneuvers, respectively.

While Kyte et al. [18] and Al-Omari and Benekhoal [19] have suggested linear functions, Chandra et al. [30] have used an exponential function for estimating minimum delay:

$$
D_{\min }=2.1955 e^{2.0868 Q_{c}}
$$

A similar approach for single lane traffic circles has also been tested by Tanyel et al. [7], where they also showed that a power function can be an adequate alternative for minimum delay estimation. Çelik [31] also suggested an exponential equation, which is derived by using the outputs of a simulation program he developed:

$$
D_{\min }=\left(T q_{c}\right)^{2} e^{1+0.23 \Delta^{2}}
$$


Ashalata and Chandra [32], by using simulation technique, tried to model minimum delay at unsignalized intersections for different priority movements under varying composition of conflicting traffic. Their results showed that delay, as experienced by a priority movement vehicles, increases with the increase of heterogeneity of conflicting flow.

Several studies have shown that minimum delay and critical gap values are highly affected from each other [33]. It is also known that critical gap acceptance value depends on the conflicting flow (circulating flow at traffic circles) and the geometric properties of the traffic circle. From this point of view, it can be said that minimum delay also highly depends on the geometric properties of an intersection. Thus Tanyel et al. [7] have developed the following empirical function, which defines the effect of geometric parameters on minimum delay at single-lane traffic circles:

$$
D_{\text {min }}=-0.042 D_{i}-0.118 w_{\text {ent }}+26.72 q_{c}+0.009 \phi
$$

where $D_{i}$ is the inscribed diameter of traffic circle $(\mathrm{m}), w_{\text {ent }}$ is the entry lane width of the minor approach $(\mathrm{m})$ and $\phi$ is the conflict angle.

From the above equation, it is clear that minimum delay $\left(D_{\min }\right)$ mainly depends on the platooning characteristics in the major stream [10], critical gap and follow-up times of vehicles in the minor stream and geometric characteristics of an intersection [7]. However, the number of entering vehicles from minor approach may also be an important parameter in estimating minimum delay as it depends on the same parameters. In Highway Capacity Manual, it is assumed that minimum delay decreases as the number of entering vehicles from minor approach increases [34, 35]:

$$
D_{\min }=\frac{1}{q_{e}}
$$

where $q_{e}$ is the capacity (entry flow) of minor approach in veh/sec. Adapting a similar approach, Akçelik [9] has suggested the following equation by using signal analogy concept:

$$
D_{\min }=\left(\left(1-T_{0} \cdot q_{e}\right) \cdot\left(\frac{e^{\lambda \cdot(T-\Delta)}}{\alpha \cdot q_{c}}-\frac{1}{\lambda}-0.5 \cdot T_{0}\right)\right.
$$

where $T_{0}$ is follow-up time for minor-stream drivers (seconds). Tanyel et al. [7] have also investigated the effect of entering vehicles on minimum delay. They used the function suggested by Horton [36] for infiltration capacity, which can be written in general form for minimum delay as:

$$
D_{\min }=D_{\min l o w}+\left(D_{\min u p}-D_{\min l o w}\right) e^{-K q_{e}}
$$


where $D_{\text {minup }}$ is the upper limit of minimum delay $(\mathrm{sec}), D_{\text {minlow }}$ is the lower limit of minimum delay (sec) and $K$ is a constant. For single-lane traffic circles, they found the function below:

$$
D_{\min }=0.100+(83.86-0.100) e^{-16.87 q_{e}}
$$

Consequently, it is clear that the studies on minimum delay at unsignalized intersections in Turkey are very limited and there are no studies on minimum delays at multi-lane traffic circles. However, an adequate minimum delay function has a great importance in estimating average delay of an approach.

As mentioned before, both theoretical and empirical approaches can be used for developing a minimum delay function. Several studies proved that theoretical and empirical models, if they are built correctly, give close results with each other [5,37]. Although theoretical models provide more detailed information about drivers' behavior, which is an important issue in traffic engineering, they have relatively complex structure. On the other hand, empirical models may provide simple and applicable solutions.

In this study, it is aimed to develop a simple model for minimum delays at traffic circles that can be used in practice; hence, several empirical functions are proposed based on different geometric parameters (inscribed diameter, entry lane width, etc.) and/or operational parameters (circulating flow, entry capacity etc.), which can be easily collected from field by practitioners.

The paper is organized as follows: i) First, study areas and data collection procedure are presented. ii) Then, the different approaches that are used to define an adequate empirical minimum delay and drivers' behavior in Turkey are described. iii) Obtained empirical models are compared with existing models, which were suggested by different researchers. iv) A discussion on the effect of geometric design parameters and critical gap acceptance on minimum delay is presented.

\section{DATA COLLECTION PROCEDURE}

In this study, the data was collected from five multi-lane traffic circles in İzmir, Turkey. Three of the traffic circles are located in Alsancak (Montrö, Lozan and Alsancak Gar), one is located in Bornova (Meydan) and one is located in Buca (Üçkuyular). Some geometric properties of traffic circles are given in Table 1. Observations were made at peak hours by using a video camera, which is located at a higher building near intersection during weekdays under dry and clear weather conditions. From video recordings data such as entry flow rate per approach $(\mathrm{veh} / \mathrm{hr})$, circulating flow rate per approach $(\mathrm{veh} / \mathrm{hr})$, headways in the circulating stream (sec), accepted and rejected gaps/lags in the circulating streams, follow-up times of entering vehicles (sec) and minimum delay values (sec) are derived.

In the literature, it is generally accepted to collect and use 15 min data sets for analysis [19, 29]. However, this approach may lead to use a limited number of data. To overcome this problem, the data extraction method is preferred instead [7, 18,30]. This method can be briefly explained as follows: 


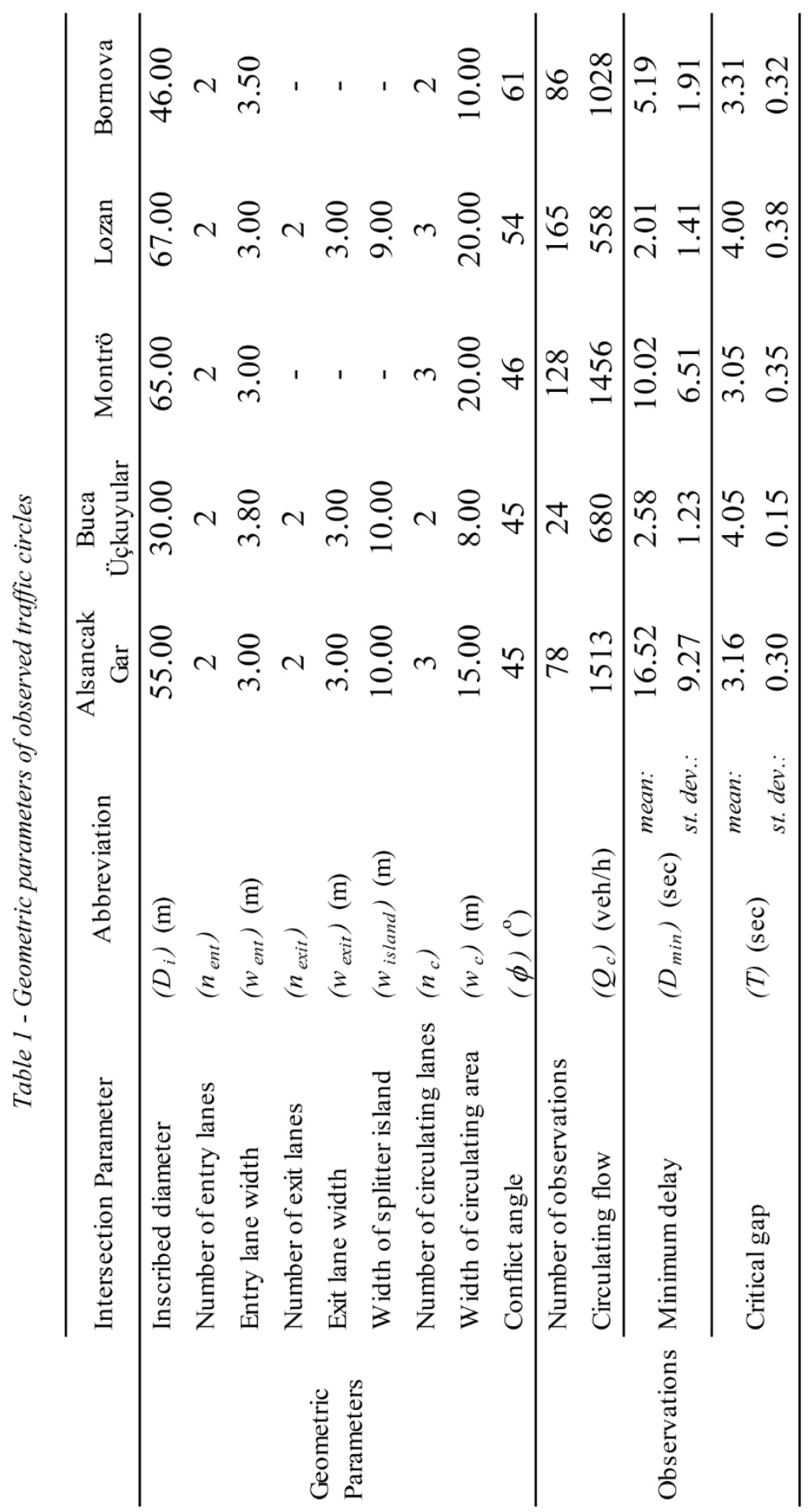


The microscopic analysis requires the definition of the conflicting traffic flow as seen by each subject approaching vehicle. If $t_{0}$ is defined as the time of arrival of the subject approaching vehicle at the reference line, $t_{d}$ is defined as the time of departure of the subject approaching vehicle, $\mathrm{n}$ is the number of observed conflicting vehicles for the subject vehicle and $t_{n}$ is the time of arrival of the $n$th conflicting vehicle at the reference point [30]. Then conflicting flow rate can be found by using the following equation:

$$
\text { Conflict flow rate }=\frac{n}{t_{n}-t_{0}}
$$

In the equation, the conflicting flow rate, which is experienced by a driver waiting at the entrance of the subject approach, is defined as the number of observed conflicting vehicles divided by the observation time [30]. The service delay then can be computed by using Eq. 26:

$$
\text { Minimum delay }=t_{d}-t_{0}
$$

Chandra et al. [30] stated that the major advantage of using disaggregate data in microscopic analysis is that, information is not lost by aggregation, and the number of data points are highly increased. Besides, it gives instantaneous conflicting flow rate as observed by a driver waiting for a suitable gap.

All the data, which include heavy vehicles in the major and/or minor flow are excluded due to the limited number of data, and observations which include only passenger cars are used in the analysis. As a result, 481 observed data in total (79 from Alsancak Gar, 24 from Buca Üçkuyular, 86 from Bornova, 128 from Montrö and 165 from Lozan) have been obtained and used in this study.

\section{PARAMETERS AFFECTING MINIMUM DELAY}

Previous studies have shown that there is a high relation between critical gap and average delay $[11,12,21]$. A similar relation may be expected between critical gap and minimum delay also. In the simplest term, critical gap can be defined as the minimum gap that all drivers in the minor stream are assumed to accept at all similar locations [10]. In Figure 1, relation between observed accepted gaps, circulating flow and minimum delay is shown. It is clear in Figure 1 that, as the accepted gap values increase, minimum delay values decrease. However, a completely opposite trend might have been expected, since vehicles would enter the main flow more easily when they accept smaller gaps. Although this assumption is true in most cases, the results presented in Figure 1 are quite valid, since they reflect drivers' behavior at unsignalized intersections. Studies have shown that under low circulating flow conditions, drivers in the minor stream tend to accept longer gaps, since they may provide safer entering opportunities. However, if they have to wait longer, they may get impatient and accept lower gap values and may also force the main stream to slow down or completely stop. These situations are named as gap forcing or limited priority merge conditions [5]. 
As mentioned before, critical gap acceptance values depend not only on circulating flow but also on geometric parameters. Collection of critical gap acceptance data from the field may be difficult but geometric parameters of a traffic circle can be measured easily. In Figure 2, geometric parameters of a multi-lane traffic circle are shown. In the figure, $D_{i}$ is inscribed diameter $(\mathrm{m}), w_{\text {ent }}$ is entry lane width $(\mathrm{m}) ; w_{\text {exit }}$ is exit lane width $(\mathrm{m}), w_{\text {island }}$ is width of the splitter island $(\mathrm{m}), w_{c}$ is circulating lane width $(\mathrm{m})$ and $\phi$ is conflict angle $\left(^{\circ}\right)$.

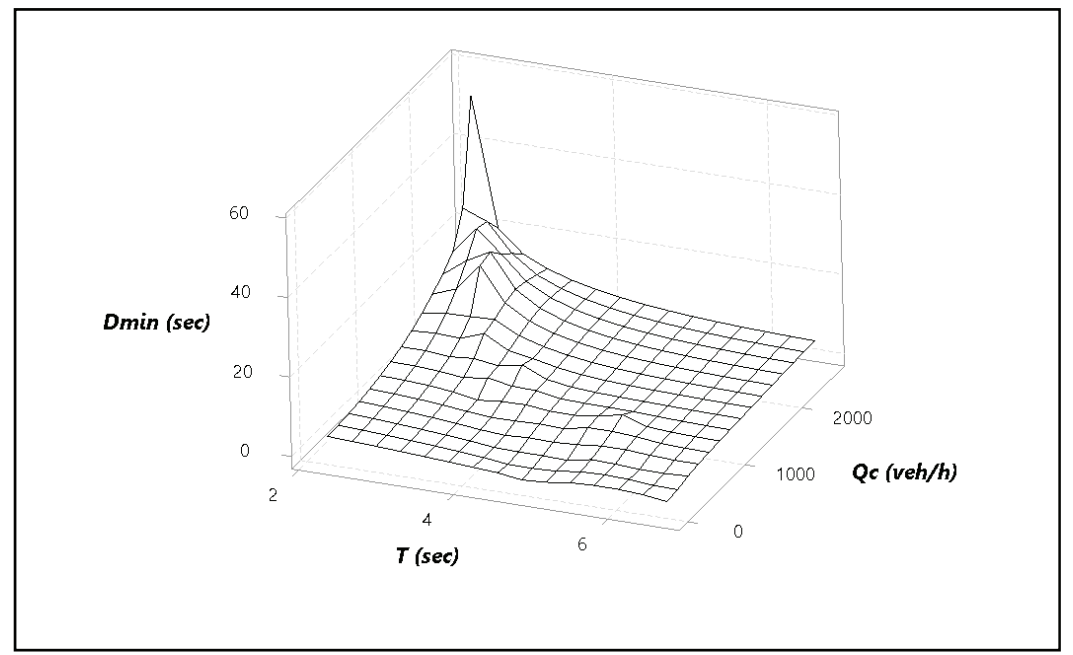

Figure 1 - Relation between accepted gaps and minimum delay values

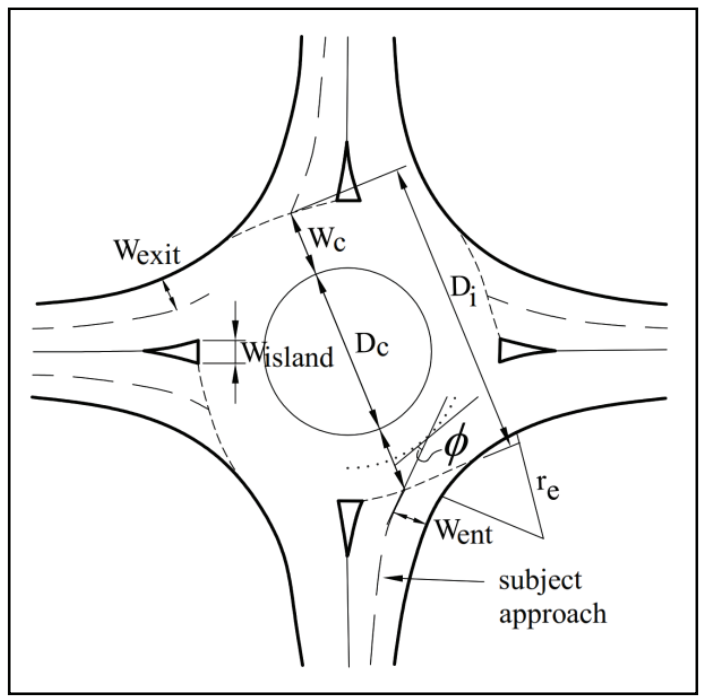

Figure 2 - Geometric parameters of a traffic circle 
Tanyel et al. [7] stated that there may be the following expectations for the effect of geometric parameters on minimum delay:

- When inscribed diameter is increased, minimum delay may be decreased.

- When entry width is increased, minimum delay may be decreased.

- When exit lane width is increased, minimum delay is decreased.

- When entry angle is increased, minimum delay is also increased.

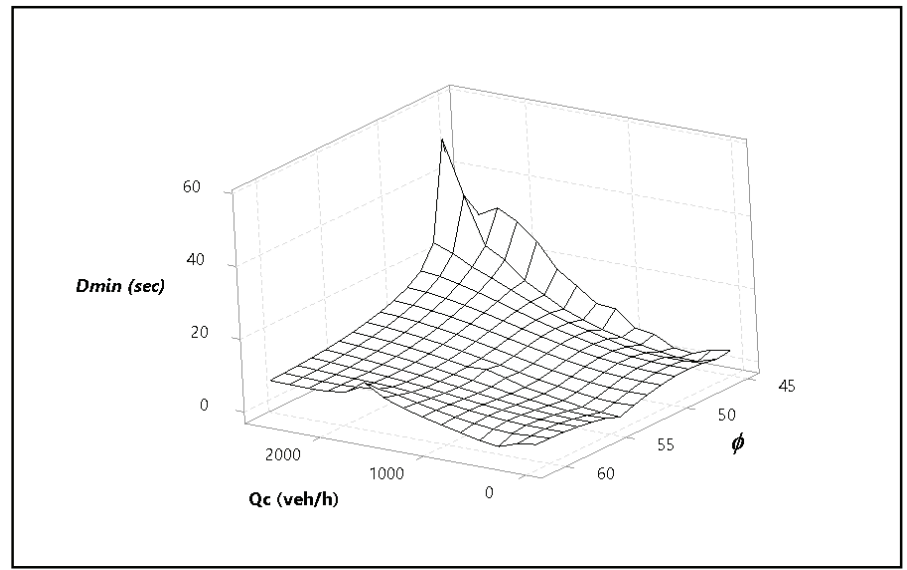

Figure 3 - Effect of entry angle on minimum delay

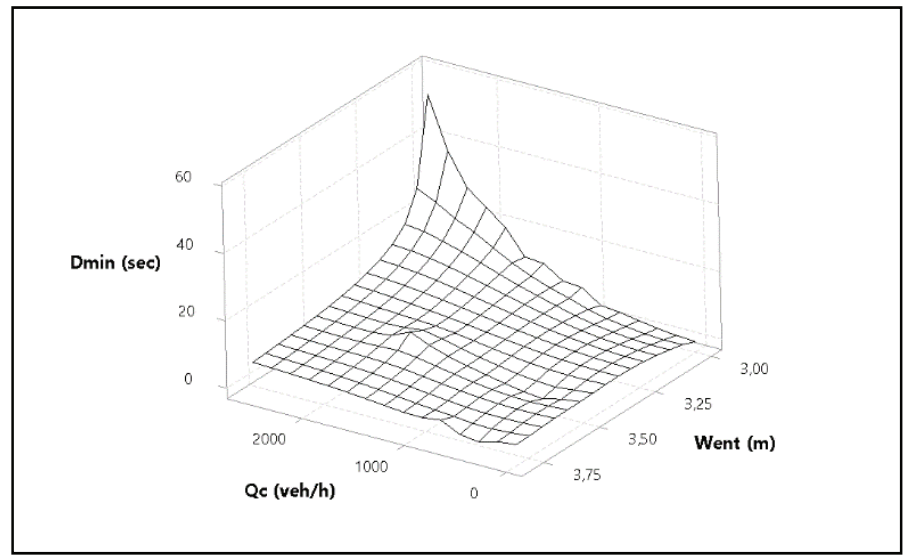

Figure 4 - Effect of entry width on minimum delay

For single-lane traffic circles Tanyel et al. [7] found that as inscribed diameter increases, minimum delay also increases which was just the opposite of the first expectation listed above. In Figures 3 5, the relationship between some of the geometric parameters and minimum delay with respect to circulating flow $\left(Q_{c}\right.$, in veh/h) are shown. From the figures, the following inferences can be made: 
- unlike the expectation defined above, as the entry angle increases, minimum delay decreases.

- as the entry width increases, minimum delay decreases.

- for low or moderate circulating flow values, as the inscribed diameter increases minimum delay decreases. However, when circulating flow exceeds $100 \mathrm{veh} / \mathrm{h}$ and reaches up to $2000 \mathrm{veh} / \mathrm{h}$, minimum delay increases with increasing inscribed diameter value. This is probably due to the result in drivers' improper lane use in the circulating stream, as the inscribed diameter increases, circulating width also increases (Figure 6). This may increase the difficulty of minor stream drivers entering the intersection.

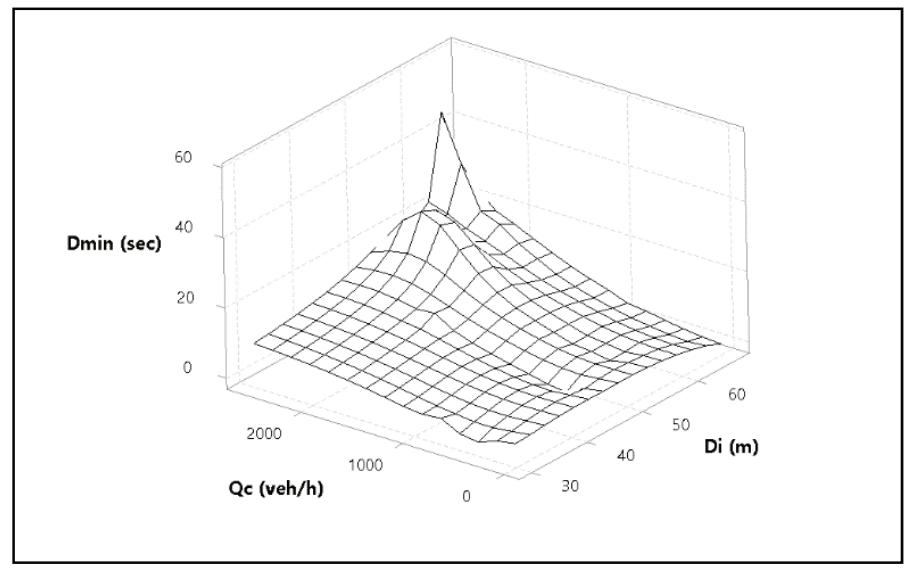

Figure 5 - Effect of inscribed diameter on minimum delay

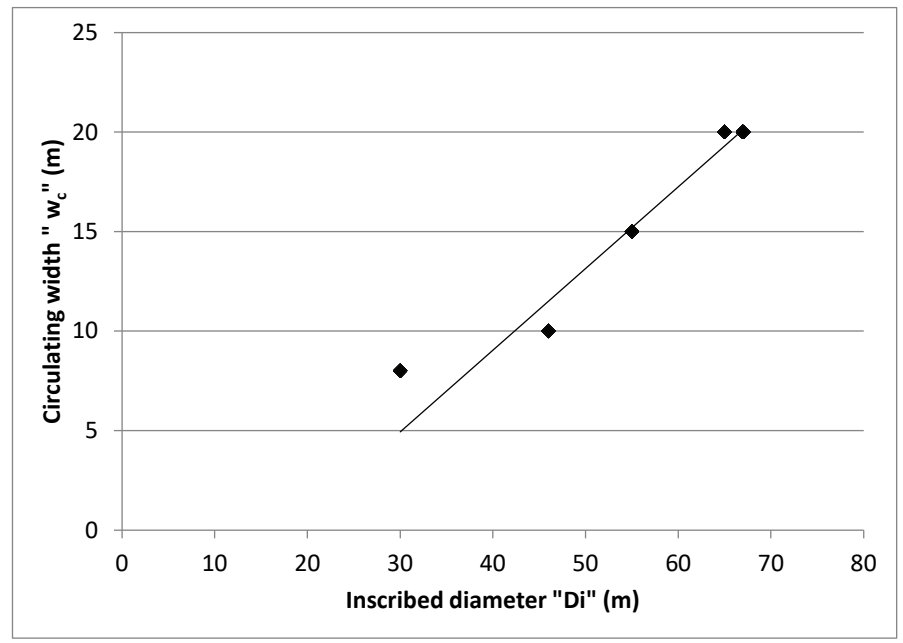

Figure 6 - Relation between inscribed diameter and circulating width 


\section{MODEL DEVELOPMENT}

In the study, models for minimum delay are developed according to three different approaches:

1. models based on circulating (conflicting) flow,

2. models based on geometric parameters and circulating flow,

3. models based on entry flow (or capacity).

\subsection{Models Based on Circulating Flow}

As explained in the introduction section, most of the empirical models are developed by investigating the relationship between minimum delay $\left(\mathrm{D}_{\min }\right)$ and circulating flow $\left(\mathrm{q}_{\mathrm{c}}\right)$. By preferring a similar approach, exponential and power functions are applied. The results are shown in Figure 7 and Equations 27and 28.

It is clear from Figure 7 that power function gives better results than exponential function but both functions fail when circulating flow exceeds $0.6 \mathrm{veh} / \mathrm{sec}$.

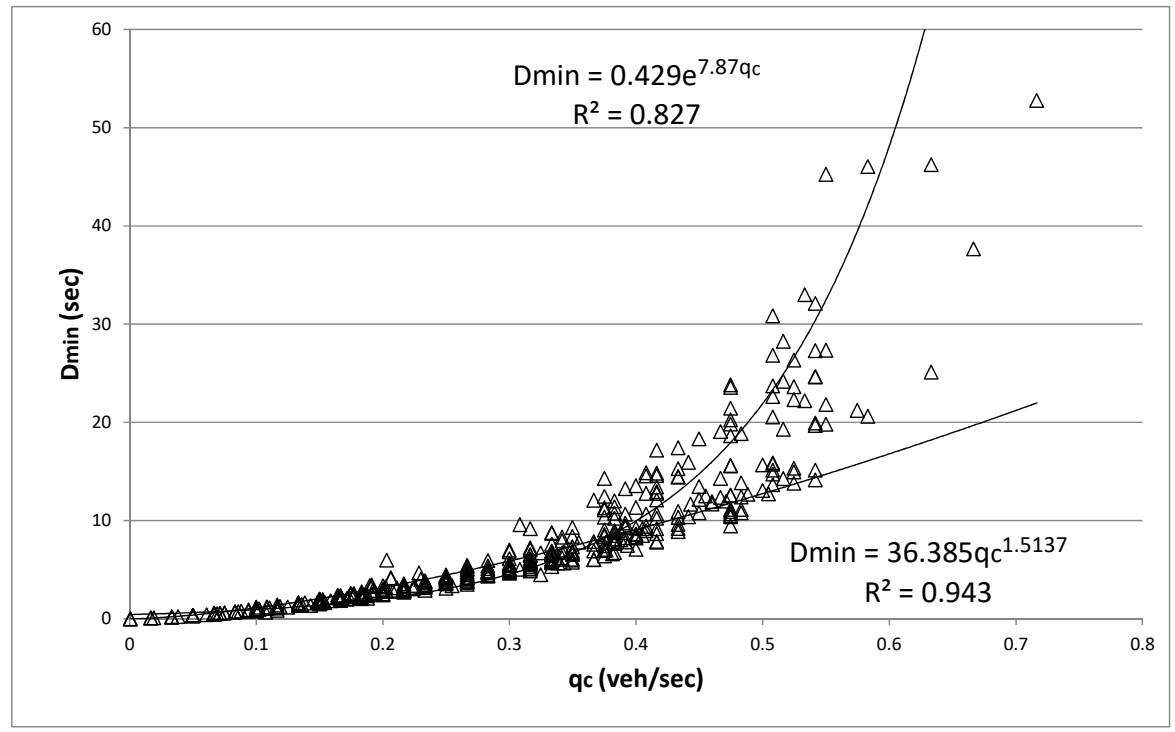

Figure 7 - Regression models developed between minimum delay and circulating flow

$$
\begin{aligned}
& D_{\text {min }}=0.429 e^{7.87 q_{c}} \\
& D_{\text {min }}=36.385 q_{c}^{1.5137}
\end{aligned}
$$




\subsection{Models Based on Geometric Parameters and Circulating Flow}

As a second step, the effect of geometric parameters on minimum delay is tried to be modeled by using multiple regression analysis. For this purpose, inscribed diameter $\left(D_{i}\right)$, entry lane width $\left(w_{\text {ent }}\right)$, exit lane width $\left(w_{\text {exit }}\right)$, width of the splitter island $\left(w_{\text {island }}\right)$, circulating lane width $\left(w_{c}\right)$ and conflict angle $(\phi)$ are chosen as independent variables along with circulating flow $\left(\mathrm{q}_{\mathrm{c}}, \mathrm{veh} / \mathrm{sec}\right)$.

Previous studies have shown that there can be a significant relationship between geometric parameters. To identify the relation between independent variables, Pearson Correlation values are calculated (Table 2). The Pearson coefficient values greater than 0.5 indicate the multicollinearity between independent variables. Bold values in the table show that, there are significant correlations between the pairs $D_{i}-w_{\text {ent }}, D_{i}-w_{c}, w_{c}-w_{\text {entry }}$ and $w_{\text {exit }}-w_{\text {island. }}$ In the analysis, these parameters are tested separately.

Table 2 - Pearson Correlation Values between geometric parameters

\begin{tabular}{lccccc}
\hline & $D_{i}$ & $w_{\text {ent }}$ & $w_{\text {exit }}$ & $w_{\text {island }}$ & $w_{c}$ \\
\hline$w_{\text {ent }}$ & $\mathbf{- 0 . 9 1 5}$ & & & & \\
$w_{\text {exit }}$ & 0.135 & -0.262 & & & \\
$w_{\text {island }}$ & 0.086 & -0.240 & $\mathbf{0 . 9 9 7}$ & & \\
$w_{c}$ & $\mathbf{0 . 9 7 3}$ & $\mathbf{- 0 . 9 0 2}$ & 0.169 & 0.126 & \\
$\phi$ & -0.170 & 0.432 & -0.123 & -0.165 & -0.339 \\
\hline
\end{tabular}

Table 3 -Multiple Regression Model 1

\begin{tabular}{|c|c|c|c|c|}
\hline & $\beta$ & Sdt.Error & $t$ Stat & P-value \\
\hline$D_{i}$ & -0.053 & 0.013 & -4.15 & 0.000 \\
\hline Wisland & 0.398 & 0.034 & 11.51 & 0.000 \\
\hline$\phi$ & -0.099 & 0.014 & -7.36 & 0.000 \\
\hline$q_{c}$ & 46.031 & 1.054 & 43.67 & 0.000 \\
\hline
\end{tabular}

Table 4 - Multiple Regression Model 2

\begin{tabular}{|c|c|c|c|c|}
\hline & $\beta$ & Sdt.Error & $t$ Stat & P-value \\
\hline $\boldsymbol{w}_{\text {ent }}$ & -2.731 & 0.136 & -20.010 & 0.000 \\
\hline Wisland & 0.388 & 0.034 & 11.535 & 0.000 \\
\hline$q_{c}$ & 47.368 & 1.093 & 43.344 & 0.000 \\
\hline
\end{tabular}


Three empirical models, which show the effect of geometry on minimum delay are obtained by using multiple regression analysis. The results of analysis are given in Tables 3, 4, 5 and models are given in Equations 29, 30 and 31 respectively. From the tables, it is clear that R-square values of all three models are very close to each other.

Table 5 - Multiple Regression Model 3

\begin{tabular}{|c|c|c|c|c|}
\hline & $\beta$ & Sdt.Error & t Stat & P-value \\
\hline$w_{e x i t}$ & 1.113 & 0.106 & 10.470 & 0.000 \\
\hline$\phi$ & -0.149 & 0.008 & -19.214 & 0.000 \\
\hline$q_{c}$ & 44.920 & 1.011 & 44.425 & 0.000 \\
\hline
\end{tabular}

Model 1

$$
D_{\min }=-0.053 D_{i}+0.398 w_{\text {island }}-0.099 \phi+46.031 q_{c}
$$

Model 2

$$
D_{\text {min }}=-2.731 w_{\text {ent }}+0.388 w_{\text {island }}+47.368 q_{c}
$$

Model 3

$$
D_{\min }=1.113 w_{\text {exit }}-0.149 \phi+44.920 q_{c}
$$

\subsection{Models Based on Entry Flow}

Minimum delay is highly affected by the decision of drivers in the minor stream. Critical gap $(T)$ and follow-up time $\left(T_{0}\right)$ values are two parameters which can be used to define driver characteristics at an unsignalized intersection. Accordingly, a strong relationship between minimum delay and entry flow can be expected.

When $D_{\min }$ values are plotted with respect to $q_{e}$ values, an exponential form is observed for multi-lane traffic circles (Figure 4). When a regression analysis is performed, an exponential function gives acceptable results as shown in Figure 8 and Equation 32:

$$
D_{\min }=71.71 e^{-14.7 q_{e}}
$$

As stated before, Tanyel et al. [7] used the function suggested by Horton [36] for infiltration capacity for modeling minimum delay. A similar approach is also followed in this study. The parameters of Horton function are found by using the "solver" feature of Excel software. The solver feature uses a nonlinear optimization code called "Generalized Reduced Gradient" which was developed by Waren and Lasdon [38, 39]. The code 
minimizes the sum of square errors between the observed and estimated pairs with a nonlinear manner. As a result, the following function is obtained:

$D_{\min }=1.21+(78.44-1.21) e^{-17.25 q_{e}}$

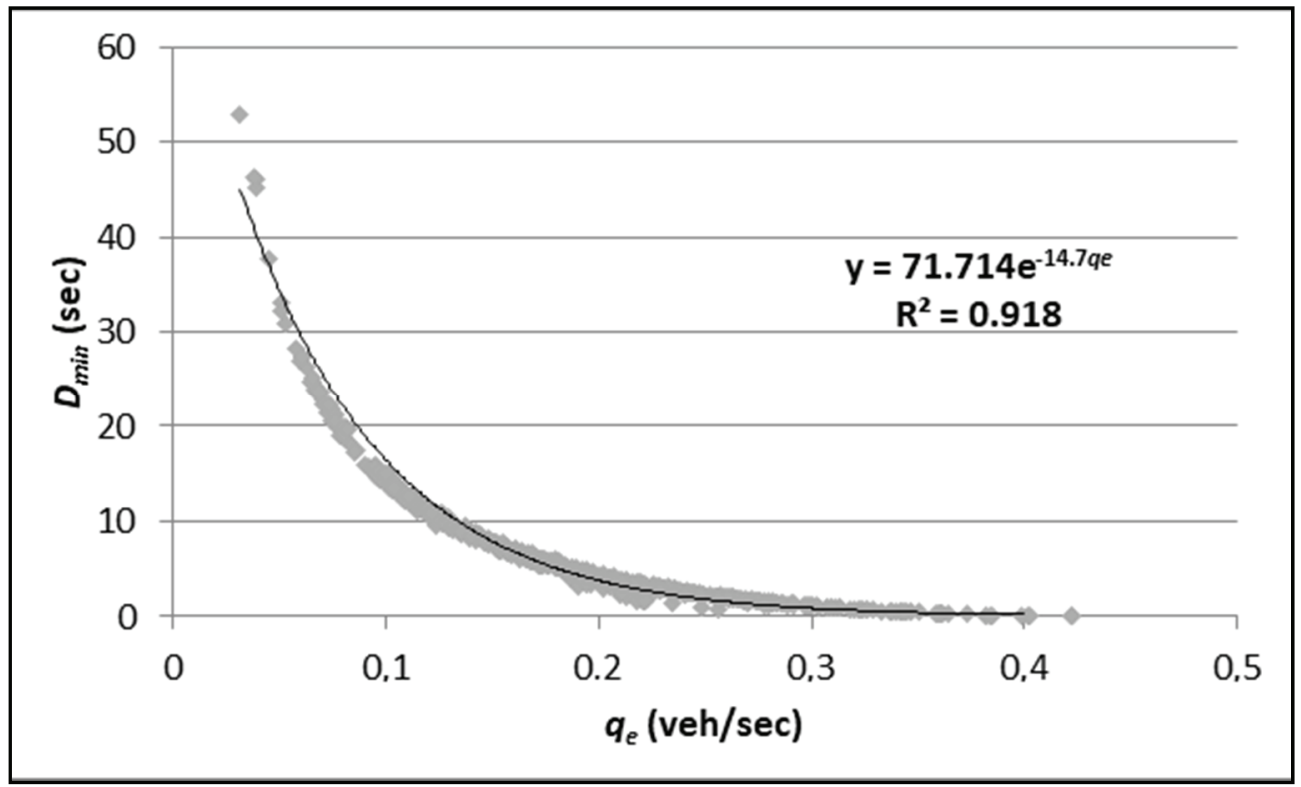

Figure 8 - Observed minimum delay values and proposed exponential function line

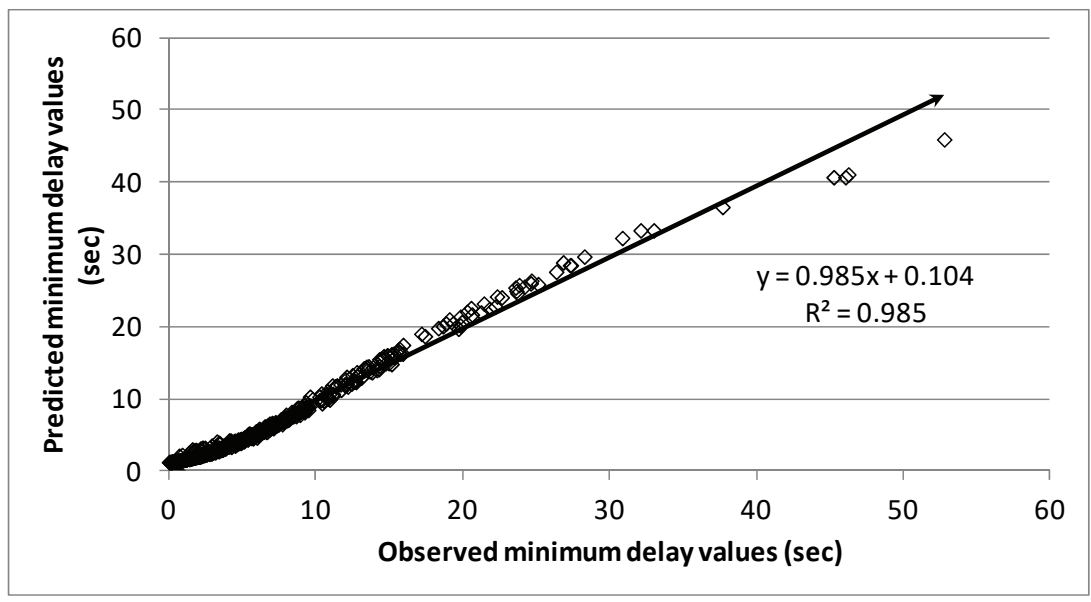

Figure 9 - Comparison of observed and estimated minimum delay values 
Estimation of the equation and observed minimum delay values are compared in Figure 9. It is clear from the figure that Horton function approach gives adequate results in estimation of minimum delay at multi-lane traffic circles.

\subsection{Comparison of Empirical Models}

In previous three sections, different empirical models are developed with different assumptions. By considering the $\mathrm{R}^{2}$ values, it can be said that the best results are obtained from Equations 17??? and 21???. Thus all models give acceptable $\mathrm{R}^{2}$ values.

However, in defining the accuracy of a model, making decisions based on only $\mathrm{R}^{2}$ values is not reliable. To define and compare the accuracy of these models, root mean square error (RMSE) and efficiency factor (EF) values are used.

Efficiency factor (EF), which is commonly known as Nash-Sutcliffe Model Efficiency Coefficient (NSE) [40] accounts for model errors in estimating the mean of the observed data set ranging from minus infinity to 1.0 . "EF $=1$ " corresponds to a perfect match of modeled values to the observed data. "EF $=0$ " indicates that the model estimations are as accurate as the mean of the observed data and an efficiency less than zero $(-\infty<\mathrm{EF}<0)$ shows worse estimation than the mean. The general equation for the model is given below:

$$
E F=1-\left(\frac{\sum_{i=1}^{N}\left(D_{\min o b s i}-D_{\text {minesti }}\right)^{2}}{\sum_{i=1}^{N}\left(D_{\min o b s i}-\bar{D}_{\min }\right)^{2}}\right)
$$

Where $D_{\text {minobs } i}$ indicates observed minimum delay value $(\mathrm{sec}), D_{\text {minest } i}$ is the estimated minimum delay value (sec), " $i$ " is the observation number and $\bar{D}_{\min }$ is the mean of observed minimum delay values ( $\mathrm{sec}$ ).

RMSE is a frequently used measure of the differences between the estimated values and the actual (observed) values and serves to aggregate the residuals into a single measure of predictive power [41]:

$$
R M S E=\sqrt{\frac{\sum_{i=1}^{N}\left(D_{\min o b s i}-D_{\min e s t i}\right)^{2}}{N}}
$$

The results of RMSE and EF are given in Table 6. It is clear that Horton function gives the best result when compared with other models. Models which depend on circulating flow give the worst results. This indicates that, models depending only circulating flow may mislead the practitioners. Circulating flow values should be validated with other parameters which have influence on minimum delay.

When circulating flow and geometric parameters are considered together, better results are obtained. Although all three models have close $\mathrm{R}^{2}$, RMSE and EF values, their accuracy is 
not sufficient. An important point is that the models developed are obtained only by using data from five intersections. In Figure $10,\left(D_{\text {minobs }}-D_{\text {minest }}\right)^{2}$ values are plotted with $D_{\text {minobs }}$ values. From the figure, it can be seen that all three models give acceptable results, where $D_{\min }$ values are below 22 seconds, but fail after this threshold.

Table 6 - Results of RMSE and EF analysis

\begin{tabular}{lcccc} 
Models & & $\mathbf{R}^{2}$ & RMSE & EF \\
\hline $\begin{array}{l}\text { Models depend on } \\
\text { circulating flow }\end{array}$ & $\mathrm{Eq}(27)$ & 0.827 & 5.239 & 0.490 \\
\cline { 2 - 5 } & $\mathrm{Eq}(28)$ & 0.943 & 4.186 & 0.675 \\
\hline $\begin{array}{l}\text { Models depend on } \\
\text { geometric parameters }\end{array}$ & $\mathrm{Eq}(29)$ & 0.892 & 3.170 & 0.813 \\
\cline { 2 - 5 } & $\mathrm{Eq}(30)$ & 0.892 & 3.218 & 0.808 \\
\hline $\begin{array}{l}\text { Models depend on } \\
\text { entry flow }\end{array}$ & $\mathrm{Eq}(31)$ & 0.888 & 3.282 & 0.800 \\
\cline { 2 - 5 } & $\mathrm{Eq}(32)$ & 0.918 & 1.222 & 0.972 \\
\hline
\end{tabular}

As stated before, best results are obtained when minimum delay is modeled by using entry flow. However, accuracy of Horton function drops for $D_{\min }$ values greater than 38 seconds. In fact, there are only 4 observed minimum delay values greater than 38 seconds. Because of insufficient number of data, Horton function fails to define $D_{\min }$ values greater than 38 seconds, but it gives better results than other empirical functions.

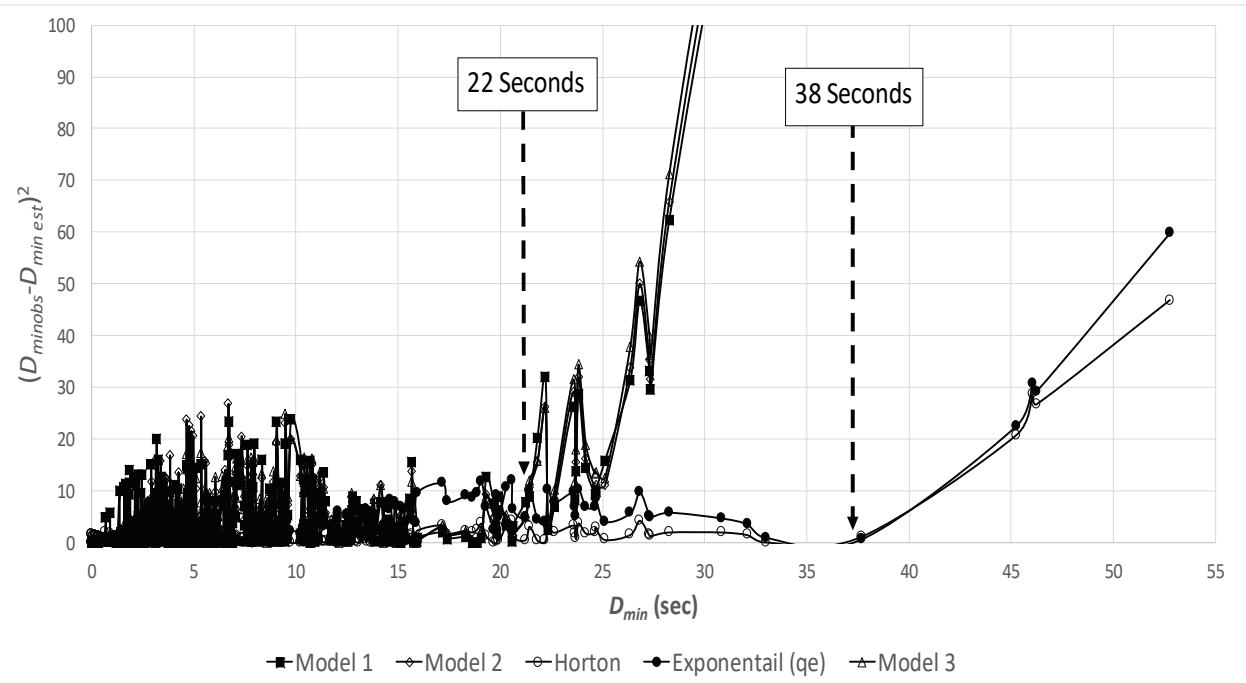

Figure 10 - Discrepancy of observed-estimated $D_{\min }$ pairs 


\section{DISCUSSION}

\subsection{Applicability of Other Models in the Literature}

By this part of the study, only derivations of empirical models are presented. However, theoretical models may give more information about drivers' behavior and interaction between different traffic flows (like circulating and entering traffic flows). Consequently, determining the ability of the theoretical models to represent observation data may also provide a better opinion about the applicability of empirical relations. For this purpose, by using the observed data, minimum headways of minor stream vehicles are calculated by means of Tanner, Troutbeck, Akçelik and Highway Capacity Manual (HCM) models.

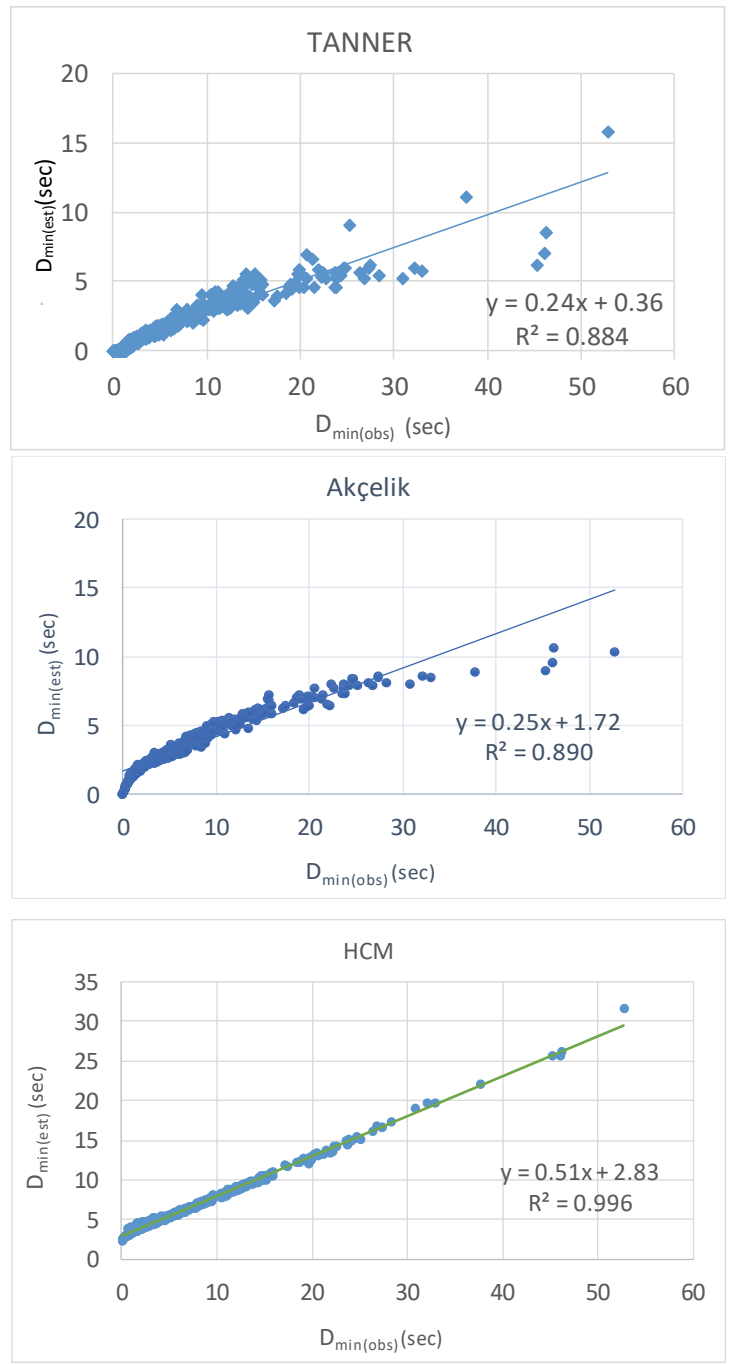

Figure 11 - Observed and estimated minimum delay values 


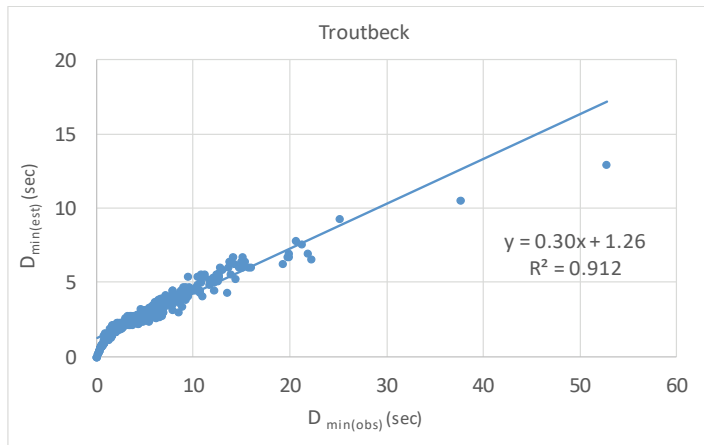

Figure 11 - Observed and estimated minimum delay values (continued)

Observed minimum delay values are compared with estimated values and their correlation are shown in Figure 11. From the figures, the following inferences can be made:

1. For a model to be acceptable, the observed and estimated values are expected to be close to each other. If a linear relationship is sought between these two data groups, the intercept of the linear function is expected to be significantly close to zero, and the slope of the line should converge significantly to one. With respect to this, it is clear from the figures that all the models fail to define the observed minimum delay values.

2. HCM model give the best results $\left(\mathrm{R}^{2}\right.$ value is very close to 1$)$ but it cannot estimate $D_{\min }$ values smaller than 2.83 seconds.

3. The second-best result is obtained from Troutbeck model but it doesn't show any significant difference from Akçelik and Tanner models.

4. These results lead to the conclusion that, it becomes necessary to conduct a detailed and comprehensive study for the calibration of theoretical models.

\subsection{Applicability of the Suggested Model to Other Multi-lane Traffic Circles}

A model, whether analytical or empirical, should also be used to determine the performance of different intersections. This can be tested by using data obtained from different intersections other than the ones used for model development. For this purpose, observations from two multi-lane traffic circles in Buca, İzmir are used. Both intersections are located on Yavuz Sultan Selim Street. Yavuz Sultan Selim 1 intersection is a traffic circle with four approaches and located at the intersection point of Yavuz Sultan Selim and Özbekistan Streets. Yavuz Sultan Selim 2 intersection is at the intersection point of Yavuz Sultan Selim and Dede Korkut Streets. Observations are made at only one approach of each intersection by using the methods defined in Section 2 of this paper. Some properties of the test circles of traffic are given in Table 7. 
Table 7 - Properties of test traffic circles

\begin{tabular}{|c|c|c|c|c|c|}
\hline & Intersection Parameter & \multicolumn{2}{|c|}{ Abbreviation } & $\begin{array}{c}\text { Yavuz Sultan Selim } \\
1\end{array}$ & Yavuz Sultan Selim 2 \\
\hline \multirow{9}{*}{$\begin{array}{l}\text { Geometric } \\
\text { Parameters }\end{array}$} & Inscribed diameter & $\left(D_{i}\right)(\mathrm{m})$ & & 37.00 & 31.50 \\
\hline & Number of entry lanes & $\left(n_{\text {ent }}\right)$ & & 2 & 2 \\
\hline & Entry lane width & $\left(w_{\text {ent }}\right)(\mathrm{m})$ & & 4.15 & 3.00 \\
\hline & Number of exit lanes & $\left(n_{\text {exit }}\right)$ & & 2 & 1 \\
\hline & Exit lane width & $\left(w_{\text {exit }}\right)(\mathrm{m})$ & & 4.50 & 3.25 \\
\hline & Width of splitter island & $\left(w_{\text {island }}\right)(\mathrm{m})$ & & 12.50 & 8.00 \\
\hline & $\begin{array}{l}\text { Number of circulating } \\
\text { lanes }\end{array}$ & $\left(n_{c}\right)$ & & 2 & 2 \\
\hline & Width of circulating area & $\left(w_{c}\right)(\mathrm{m})$ & & 9.78 & 8.75 \\
\hline & Conflict angle & $(\phi)\left({ }^{\circ}\right)$ & & 41 & 58 \\
\hline \multirow{6}{*}{ Observations } & Number of observations & & & 37 & 45 \\
\hline & Circulating flow & $\left(Q_{c}\right)(\mathrm{veh} / \mathrm{h})$ & & 744 & 828 \\
\hline & \multirow{2}{*}{ Minimum delay } & \multirow{2}{*}{$\left(D_{\min }\right)(\mathrm{sec})$} & mean: & 3.07 & 4.66 \\
\hline & & & st. dev.: & 1.31 & 2.06 \\
\hline & \multirow{2}{*}{ Critical gap } & \multirow{2}{*}{ (T) $(\mathrm{sec})$} & mean: & 3.49 & 4.43 \\
\hline & & & st. dev.: & 0.28 & 0.35 \\
\hline
\end{tabular}

82 minimum delay values in total (37 from Yavuz Sultan Selim 1, 45 from Yavuz Sultan Selim 2) are obtained from the test intersections. Observed delay values are compared with the values estimated by using Horton's function and the results are shown in Figure 12. Analysis showed that Horton function can be applied to multi-lane traffic circles with different geometries and different traffic characteristics.

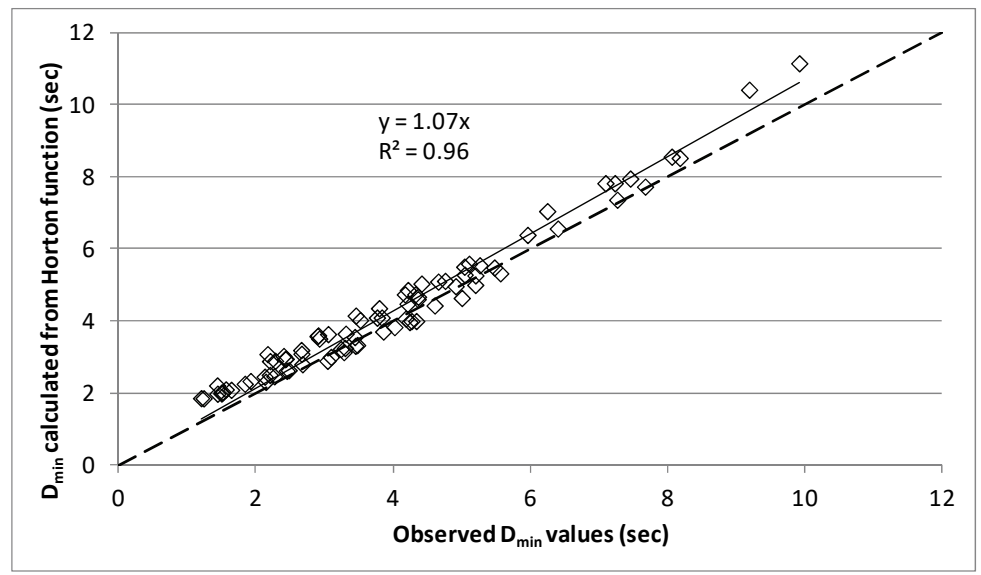

Figure 12 - Comparison of observed and estimated $D_{\min }$ values for test traffic circles 


\subsection{Comparison of Minimum Delay Models for Single- and Multi-lane Traffic Circles}

In this study, although the effect of geometric parameters of multi-lane traffic circles on minimum delay values is evaluated, perhaps one of the most important geometric parameters hasn't been discussed: number of circulating lanes.

Analysis up to this point has shown that Horton function can be an important tool in modeling of minimum delays at traffic circles, which is initially suggested by Tanyel et al. [7]. In Figure 13, estimated minimum delay values of single and multi-lane traffic circles for different entry flow values are presented. Both models give very close results, especially for entry flows between 400 and $600 \mathrm{veh} / \mathrm{h}$. Differences between two models can be seen for high or low entry flow values. Thus, RMSE and EF values for single lane model are calculated as 1.24 and 0.972 , respectively.

This similarity is a result of the nature of the data. In both cases (for single-lane and multilane traffic circles) minimum delay values are obtained for each entry lane separately. Accordingly, these results may indicate that the vehicles entering from two different lanes in an approach of a multi-lane traffic circle are not affected by each other, but other factors like circulating flow rate, critical gap acceptance, etc. are also valid for single-lane traffic circles.

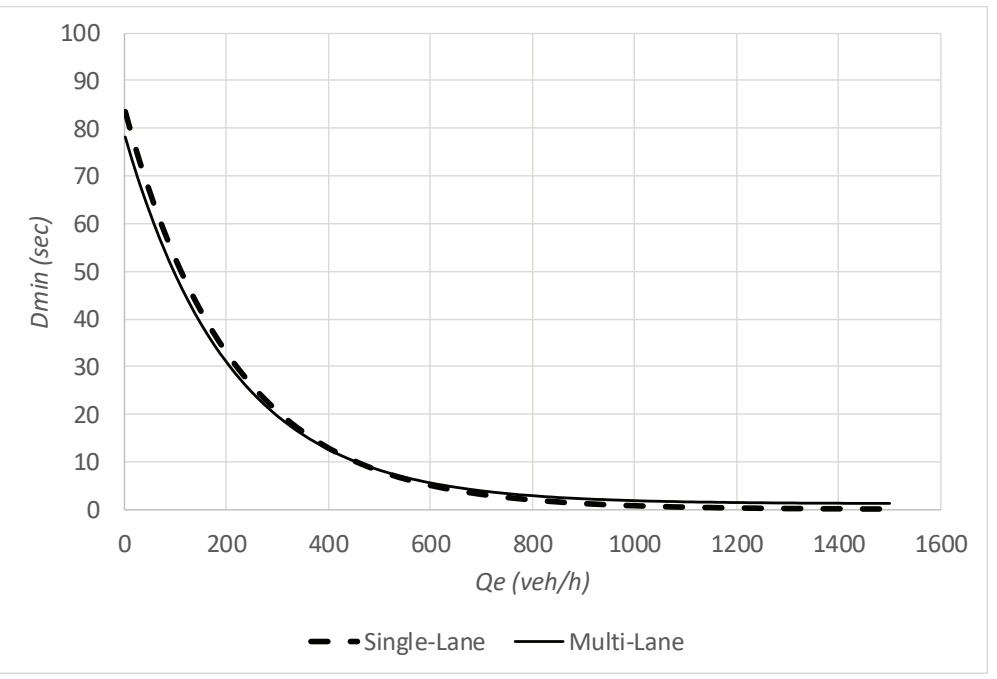

Figure 13 - Comparison of models for single-lane and multi-lane traffic circles

\section{CONCLUSIONS}

In this study, a new empirical minimum delay function for multi-lane traffic circles in İzmir, Turkey is presented. For this purpose, observations made at five multi-lane roundabouts at the city center of İzmir, Turkey. The obtained results are listed as follows:

- Although the models which depend on only circulating flow are simple and easy to apply, they have a very low accuracy in estimation of minimum delay at multi- 
lane traffic circles. This indicates that circulating flow alone cannot be used in modelling minimum delay.

- On the other hand, models which depend on geometric variables and circulating flow give better results, but they all fail to define minimum delay values greater than 22 seconds. At this point we should mention that the data was limited to only five approaches of five multi-lane traffic circles. If the number of observed intersections is increased, better calibrated models can be obtained. This may be a motive for future studies.

- Results have shown that Horton's function gives the best results in estimation of minimum delay at traffic circles. Yet, the number of entering vehicles highly depends on many variables such as circulating flow, gap acceptance characteristics of minor stream drivers, etc. If the entry flow values are desired to be obtained from observations, there should be a constant queue of vehicles at the entrance of the observed approach for at least 30 minutes (which is the case when data was collected for this study). This type of data is collected when empirical capacity function is attempted to be obtained or for calibration of a function, which is derived according to critical gap acceptance method. It can be said that minimum delay models which are based on entry flow should be used in conjunctions with the entry capacity models. This means that an entry capacity model should be developed or calibrated in future studies.

\section{Symbols}

$D_{a v} \quad$ : average delay per vehicle (seconds)

$D_{i} \quad$ : inscribed diameter of a traffic circle (m)

$D_{\text {min }} \quad:$ minimum delay (seconds)

$D_{\text {minlow }}$ : lower limit of minimum delay (sec)

$D_{\text {minup }} \quad$ : upper limit of minimum delay ( $\left.\mathrm{sec}\right)$

$K \quad:$ a constant in Horton's function

$k \quad$ : Erlang number

$\mathrm{n} \quad$ : the number of observed conflicting vehicles for the subject vehicle

$q_{c} \quad:$ major stream flow (veh/sec)

$q_{e} \quad$ : capacity (entry flow) of minor approach (veh/sec)

$T \quad$ : critical gap (seconds)

$T_{0} \quad$ : follow-up time (seconds)

$t_{d} \quad:$ the time of departure of the subject approach vehicle

$t_{0} \quad$ : the time of arrival of the subject approach vehicle at the reference line

$t_{n} \quad:$ the time of arrival of $n$th conflicting vehicle at the reference point

$w_{c} \quad$ : circulating lane width $(\mathrm{m})$

$w_{\text {ent }} \quad$ : entry lane width of the minor approach (m) 


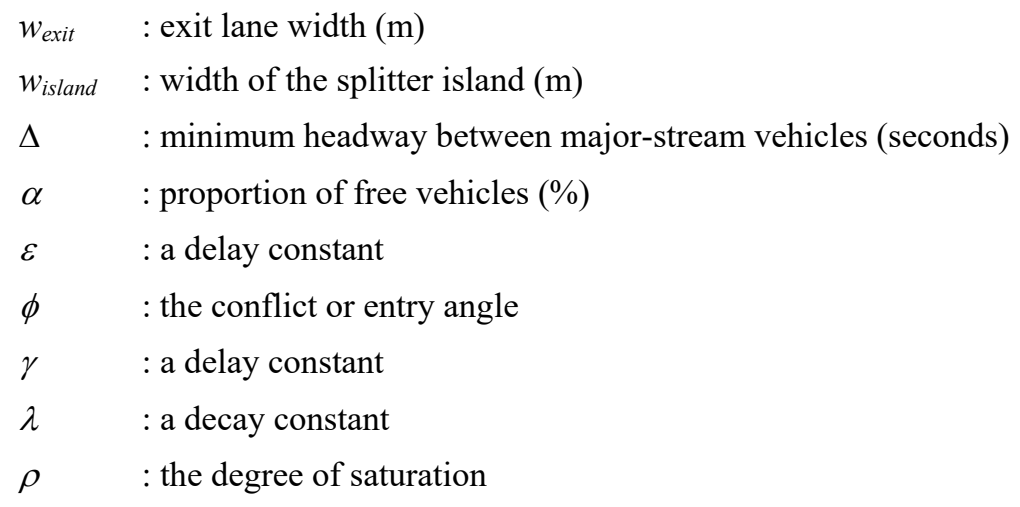

\section{References}

[1] Tanyel, S., Baran, T. and Özuysal, M. (2007). Applicability of various capacity models for single-lane roundabouts in Izmir, Turkey. Journal of Transportation Engineering, Vol. 133(2), pp. 647-653.

[2] Özuysal, M., Caliskanelli, S.P., Tanyel, S. and Baran, T. (2009). Capacity estimation for traffic circles. Applicability of ANN. Proceedings of ICE-Transport, Vol. 162(4), pp. 195-206.

[3] Çalışkanelli, S.P., Özuysal, M., Tanyel, S. and Yayla, N. (2009). Comparison of different capacity models for traffic circles. Transport, Vol. 24(4), pp. 257-264.

[4] Tanyel, S., Yayla, N., (2003). A discussion on the parameters of Cowan M3 distribution for Turkey, Transportation Research Part A: Policy and Practice, 37(2), 129-143.

[5] Tanyel, S. and Yayla, N. (2010). Yuvarlakada kavşakların kapasiteleri üzerine bir tartışma. Teknik Dergi, Vol. 21(1), pp. 4935-4958.

[6] Ersoy, M. and Çelikoğlu, H. (2014). Çok şeritli dönel kavşaklarda kapasite analizi: Highway Capacity Manual 2010 kapasite modeliyle bir değerlendirme. Pamukkale Üniversitesi Mühendislik Bilimleri Dergisi, Vol. 20(6), pp. 225-231.

[7] Tanyel, S., Celik, K., Özuysal, M. and Çalışkanelli S. P. (2013). Different approaches to minimum delay estimation at single-lane traffic circles in İzmir, Turkey. Canadian Journal of Civil Engineering, Vol. 40(3), pp. 274-284.

[8] Akgüngör, A.P. (2004). Sinyalize kavşaklarda gecikme tahmininin matematiksel modellemesi-I: Farklı çözümleme süreleri için zamana bağli yeni bir gecikme modeli. Teknoloji, Vol. 7(3), pp. 369-379.

[9] Akçelik, R. (1998). Traffic circles: Capacity and performance analysis, ARRB Research report ARR 321, Vermont, Australia. 
[10] Troutbeck, R. and Brilon, W. (1995). Unsignalized intersection theory. In Traffic Flow Theory: A State of Art Report 8-1, Eds. Gartner, N., Messer, C.J and Rathi, A. K., pp. 8-44.

[11] Troutbeck, R. J. (1990). Traffic interactions at traffic circles. Conference of the Australian Road Research Board, NPT-5, Traffic Engineering and Planning, pp. 1742.

[12] Troutbeck, R. (1991). Unsignalized intersections and traffic circles in Australia: Recent developments. Intersections Without Traffic Signals II, pp. 238-257, Bochum, Germany.

[13] Cowan, R. C. (1987). An extension of Tanner's results on uncontrolled intersections. Queueing Systems, Vol. 1, pp. 249-263.

[14] Luttinen, R. T. (2004). Capacity and level of service at Finnish unsignalized intersections. Finra Reports 1/2004, Finnish Road Administration, Helsinki, Finland.

[15] Gerlough, D. L. and Huber, M. J. (1975). Traffic flow theory. Transportation Research Board Special Report 165, Washington D.C., USA.

[16] Surti, V. H. (1970). Operation efficiency efficiency evaluation of selected at-grade intersectections. HHR 321, pp. 60-73, Highway Research Board, National Research Council, Washington, D.C.

[17] Teply, S., Abou-Henaidy, M. I., Hunt, J. D. (1997). Gap acceptance behaviouraggregate and logit perspectives: Part 2. Traffic Engineering and Control, Vol. 38(10), pp. 540-544.

[18] Kyte, M., Clemow, C., Mahfood, N., Lall, B. K. and Khisty, C. J. (1991). Capacity and delay characteristics of two-way stop-controlled intersections. Transportation Research Record 1320, Transportation Research Board, National Research Council, Washington, D.C. pp. 160-167.

[19] Al-Omari, B. and Benekohal, R. F. (1999). Hybrid delay models for unsaturated twoway stop controlled intersections. Journal of Transportation Engineering, Vol. 125(4), pp. 292-293.

[20] Adams, W. F. (1936). Road traffic considered as a random series. Journal of the Institution of Civil Engineers, Vol. 4(1), pp. 121-130.

[21] Tanner, J.C. (1962). A theoretical analysis of delays at an uncontrolled intersection. Biometrika, Vol. 49(1-2), pp. 163-170.

[22] Cowan R. J. (1975). Useful headway models. Transportation Research, Vol. 9, pp. 371-375.

[23] Cowan, R. J. (1984). Adam's formula revised. Traffic Engineering and Control, Vol. 25 (5), pp. 272-274.

[24] Luttinen R. T. (1996). Statistical analysis of vehicle time headways. Teknillien Korkeakoulu, Julkaisu, , Liikennetekniikka, Otaniemi, Finland.

[25] Drew, D. R. (1968). Traffic flow theory and control. McGraw-Hill, New York. 
[26] Gedizlioğlu, E. (1979). Denetimsiz kavşaklarda yan yol sürücülerinin davranışlarına göre pratik kapasite saptanması için bir yöntem. Doktora Tezi, İ.T.Ü. MühendislikMimarlık Fakültesi, İstanbul.

[27] Troutbeck, R. J. (1986). Average delay at an unsignalized intersction with two major streams each having a dichotomized headway. Transportation Science, Vol. 20(4), pp. 272-286.

[28] Hagring, O. (2003). Capacity model for traffic circles. Trivector Report 2003:7, Lund, Sweden.

[29] Flannery, A., Kharoufeh, J. P., Gautam, N. and Elefteriadou, L. (2005). Queuing delay models for single-lane traffic circles. Civil Engineering and Environmental Science, Vol. 22(3), pp. 133-150.

[30] Chandra, S., Agrawal, A. and Rajamma, A. (2009). Microscopic analysis of service delay at uncontrolled intersections in mixed traffic conditions. Journal of Transportation Engineering, Vol. 135(6), pp. 323-329.

[31] Çelik, F. (1987). Denetimsiz eşdüzey kavşak sisteminin simülasyonu ve taşıt gecikmelerinin formüle edilmesi. Doktora Tezi, İ.T.Ü. Fen Bilimleri Enstitüsü, İstanbul.

[32] Ashalatha R. and Chandra, S. (2011). Service delay analysis at TWSC intersections through simulation. KSCE J. of Civ. Eng., Vol. 15(2), pp. 413-425.

[33] Kittelson, W.K. and Vandehey, M.A. (1991). Delay effects on driver gap acceptance characteristics at two-way stop-controlled intersections. Transportation Research Record 1320, pp. 154-159.

[34] Transportation Research Board (TRB). (2000) Highway Capacity Manual. National Research Council, Washington D.C., U.S.A.

[35] Transportation Research Board (TRB). (2010) Highway Capacity Manual. National Research Council, Washington D.C., U.S.A.

[36] Horton, R.E. (1940). An approach toward a physical interpretation of infiltration capacity. Soil Science Society of America Journal, Vol. 5, pp. 399-417.

[37] Kimber R. M. (1980). The traffic capacity of roundabouts. Transport and Road Research Laboratory, Report 942, Crowthorne, England.

[38] Waren, A. D. and Lasdon, L. S. (1979). The status of nonlinear programming software. Operations Research, Vol. 27 (3), pp. 431-456.

[39] Lasdon, L. S. and Waren, A.D. (1983). Large scale nonlinear programming. Computers and Chemical Engineering, Vol. 7(5), pp. 595-604.

[40] Nash, J. E., Sutcliffe, J. V. (1970). River flow forecasting through conceptual models part I - A discussion of principles. Journal of Hydrology, Vol. 10 (3), pp. 282-290.

[41] Barnston, A. G. (1992). Correspondence among the correlation RMSE (root mean square error) and Heidke forecast verification measures; refinement of the Heidke score. Notes and Correspondence, Vol. 7(4), pp. 699-709. 